\title{
Psychophysiological responses to various slow, deep breathing techniques
}

Citation for published version (APA):

Gholamrezaei, A., Van Diest, I., Aziz, Q., Vlaeyen, J. W. S., \& Van Oudenhove, L. (2021).

Psychophysiological responses to various slow, deep breathing techniques. Psychophysiology, 58(2), [e13712]. https://doi.org/10.1111/psyp.13712

Document status and date:

Published: 01/02/2021

DOI:

10.1111/psyp.13712

Document Version:

Publisher's PDF, also known as Version of record

Document license:

Taverne

Please check the document version of this publication:

- A submitted manuscript is the version of the article upon submission and before peer-review. There can be important differences between the submitted version and the official published version of record.

People interested in the research are advised to contact the author for the final version of the publication, or visit the DOI to the publisher's website.

- The final author version and the galley proof are versions of the publication after peer review.

- The final published version features the final layout of the paper including the volume, issue and page numbers.

Link to publication

\footnotetext{
General rights rights.

- You may freely distribute the URL identifying the publication in the public portal. please follow below link for the End User Agreement:

www.umlib.nl/taverne-license

Take down policy

If you believe that this document breaches copyright please contact us at:

repository@maastrichtuniversity.nl

providing details and we will investigate your claim.
}

Copyright and moral rights for the publications made accessible in the public portal are retained by the authors and/or other copyright owners and it is a condition of accessing publications that users recognise and abide by the legal requirements associated with these

- Users may download and print one copy of any publication from the public portal for the purpose of private study or research.

- You may not further distribute the material or use it for any profit-making activity or commercial gain

If the publication is distributed under the terms of Article $25 \mathrm{fa}$ of the Dutch Copyright Act, indicated by the "Taverne" license above, 


\title{
Psychophysiological responses to various slow, deep breathing techniques
}

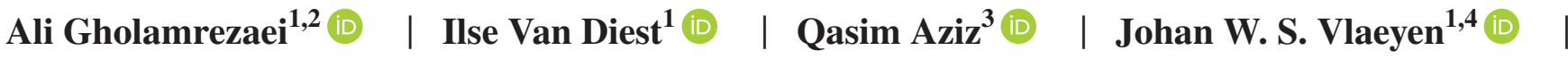 \\ Lukas Van Oudenhove ${ }^{2}$ (i)
}

${ }^{1}$ Research Group Health Psychology, Faculty of Psychology and Educational Sciences, KU Leuven, Leuven, Belgium

${ }^{2}$ Laboratory for Brain-Gut Axis Studies, Translational Research Center for Gastrointestinal Disorders, Department of Chronic Diseases, Metabolism and Ageing, KU Leuven, Leuven, Belgium

${ }^{3}$ Centre for Neuroscience, Surgery and Trauma, Blizard Institute, Wingate Institute of Neurogastroeneterology, Barts and The London School of Medicine and Dentistry, Queen Mary University of London, London, UK

${ }^{4}$ Experimental Health Psychology, Faculty of Psychology and Neuroscience, Maastricht University, Maastricht, The Netherlands

\section{Correspondence}

Ali Gholamrezaei, Research Group Health Psychology, Faculty of Psychology and Educational Sciences, Tiensestraat 102, box 3726, Leuven 3000, Belgium.

Email: ali.gholamrezaei.63@gmail.com

\section{Funding information}

Research Council KU Leuven (DBOF/14/020); Flemish Government, Belgium "Asthenes" long-term structural funding-Methusalem grant (Meth/15/011)

\begin{abstract}
Deep breathing exercises are commonly used for several health conditions including pain and hypertension. Various techniques are available to practice deep breathing, whereas possible differential psychophysiological effects have not been investigated. We compared four deep breathing techniques and examined outcomes in blood pressure variability, respiratory sinus arrhythmia, baroreflex function, and emotional state. Healthy adult volunteers performed pursed-lips breathing, left and right unilateral nostril breathing, and deep breathing with an inspiratory threshold load (loaded breathing), all at a frequency of $0.1 \mathrm{~Hz}$ (i.e., controlled breathing) and for three minutes each. Results showed that blood pressure variability was higher during loaded breathing versus other conditions and higher during pursed-lips breathing versus left and right unilateral nostril breathing. Respiratory sinus arrhythmia was higher during loaded breathing versus other conditions and higher during pursed-lips breathing versus left unilateral nostril breathing. The effect of breathing condition on respiratory sinus arrhythmia was mediated by alterations in blood pressure variability. There was no difference between the breathing conditions in baroreflex sensitivity or effectiveness. Participants rated pursed-lips breathing as more calming and pleasant and with more sense of control (vs. other conditions). Overall, among the four tested deep breathing techniques, loaded breathing was associated with enhanced cardiovascular effects and pursed-lips breathing with better emotional responses, while also enhancing cardiovascular effects (albeit less than loaded breathing). These findings can be informative in applying deep breathing techniques as self-management interventions for health conditions, in which baroreceptors stimulation and autonomic and emotional modulations can be beneficial, such as pain and hypertension.
\end{abstract}

\section{K E Y W O R D S}

autonomic, baroreflex, breathing exercise, heart rate variability, hypertension, pain

\section{1 | INTRODUCTION}

Breathing exercises concern an active process of taking conscious control over timing and/or volume components of respiration. According to a national survey in the United States, [slow and] deep breathing exercises (SDB) ${ }^{1}$ are the second most common complementary health approaches and the

\footnotetext{
${ }^{1}$ Deep breathing exercise is usually performed at slower breathing frequencies, around $\sim 0.1 \mathrm{~Hz}$ ( $\sim 6$ breaths per minute). In many literatures, including this one, it is called slow, deep breathing (SDB).
} 
most common mind and body practices used by adults. Deep breathing exercises are often used as interventions on their own or as components of other non-pharmacological treatments such as relaxation, hypnosis, meditation, yoga, tai chi, and qi gong (Jackson, 2015). Pain (Clarke et al., 2016; Nahin et al., 2015), hypertension (Brook et al., 2013; Prasad et al., 2013), anxiety (Bystritsky et al., 2012; Kessler et al., 2001), and stress (Druss \& Rosenheck, 2000) are common health-related conditions for which these complementary approaches are used.

Some evidence on the attenuation of pain during SDB has been reported (Chalaye et al., 2009; Jafari et al., 2020; Martin et al., 2012; Zautra et al., 2010). However, the underlying mechanisms are not completely understood and they seem to be multifactorial including cognitive, emotional, and autonomic modulations by SDB (Jafari et al., 2017). Several studies have shown that practicing SDB reduces blood pressure and heart rate in the long-term (for review see Prasad et al., 2013), and the arterial baroreceptors' reflex, the baroreflex, seems to be a mediating neural mechanism in this regard. The baroreflex is responsible for the rapid control of arterial blood pressure. Arterial (high-pressure) baroreceptors are mechanoreceptors mainly located in the aortic arch and carotid sinus. These receptors sense the changes in blood pressure and convert the mechanical signals (the degree of the arterial walls stretch) into an action potential frequency. An increase in blood pressure leads to increased baroreceptors afferent signaling via the aortic depressor and carotid sinus nerves to the nucleus of the solitary tract in the brain stem. This leads to decreased sympathetic and increased cardiovagal outputs and ultimately a decrease in heart rate, cardiac output, vascular tone, and blood pressure (Mohrman \& Lois, 2018). Long-term practice of SDB is associated with an increased baroreflex sensitivity and cardiac parasympathetic activity and a decreased sympathetic activity which are suggested as the mechanisms for the effects of SDB on blood pressure and heart rate in hypertensive patients (Bernardi et al., 2002; Fonkoue et al., 2018; Harada et al., 2014; Joseph et al., 2005; Modesti et al., 2015). Baroreceptors stimulation and autonomic modulations are also proposed as possible mechanisms underlying the hypoalgesic effects of SDB (Botha et al., 2015; Jafari et al., 2017), and the nucleus of the solitary tract which has projections to brain areas involved in pain regulation is suggested as the main neural gateway (Bruehl \& Chung, 2004).

Various techniques are available for practicing SDB. Some (health) practices, for example, vocal prayers and yoga mantras, may also involve altering breathing parameters similar to what is seen during SDB (Bernardi et al., 2001). Techniques of SDB may vary in breathing frequency, inspiration to expiration ratio, or may use nasal or oral breathing. In the pursed-lips breathing (PLB) technique, for example, inspiration is performed through the nose and expiration through the mouth while pursing the lips (Spahija \& Grassino, 1996). The PLB technique is commonly used during rehabilitation of patients with chronic obstructive pulmonary disease considering its beneficial effects on pulmonary function (Holland et al., 2012). Another SDB technique is unilateral nostril breathing (UNB) which is commonly used in yoga and meditation (Brown \& Gerbarg, 2009). The UNB technique involves inspiration via one nostril and expiration via the same or the other nostril. Some studies have shown an increase in cardiac vagal activity and a reduction in blood pressure in response to UNB (Brandani et al., 2017). Furthermore, some studies have reported differential effects of breathing via the left or right nostril, with the left UNB associated with a stronger increase in cardiac vagal activity and reduction in blood pressure (Pal et al., 2014; Raghuraj \& Telles, 2008). However, findings have not been consistent in this regard and the mechanism is not clear yet. The cyclical alteration in airflow dominance between the right and left nostrils (also called as nasal cycle) associated with lateralized rhythms in autonomic activity is proposed as a possible mechanism in this regard (Price \& Eccles, 2016; Shannahoff-Khalsa, 1991), though definitive evidence confirming this is lacking.

Inspiratory threshold loading (ITL) is used for muscle training during rehabilitation in patients with chronic obstructive pulmonary disease (Decramer, 2009). Recently, clinical trials have combined ITL with SDB (loaded SDB) for the management of hypertension and have found better results (decrease in blood pressure and heart rate) with loaded SDB, when is practiced for several weeks, compared to SDB without load (Jones et al., 2010; Ublosakka-Jones et al., 2018). We recently showed that using an ITL during SDB further increases blood pressure variability at the frequency of breathing followed by increased respiratory sinus arrhythmia (RSA). Although we found no further change in baroreflex sensitivity by using ITL, with the baroreflex operating within a larger range of blood pressure fluctuations, the application of ITL during SDB can enhance stimulation of the arterial (high-pressure) baroreceptors (Gholamrezaei et al., 2019). These responses may explain the beneficial effects of loaded SDB in patients with hypertension and may also extend to pain as stimulation of the baroreceptors and autonomic modulation during SDB are proposed to have hypoalgesic effects (Jafari et al., 2017).

Different SDB techniques may have different effects on the cardiovascular and autonomic systems, and therefore, may produce different outcomes for pain and hypertension management. The present study aimed to compare the influence of four SDB techniques (PLB, left and right UNB, and loaded SDB) on cardiovascular and autonomic parameters including blood pressure and heart rate (and variability), and baroreflex function. Further, we compared the emotional impact of these SDB techniques including the dimensions arousal, valence, and dominance. This study had two 
priori hypotheses: (1) considering that closing one nostril increases the resistance to airflow and works as a resistive load (Pallanch et al., 1985), and based on our previous findings on loaded SDB (Gholamrezaei et al., 2019), we hypothesized that blood pressure and heart rate variability would be higher during UNB and loaded SDB versus PLB; and (2) since nasal breathing is more ecologically valid than mouth breathing in a resting state (Gilbert, 2014), we hypothesized that UNB and PLB would be associated with less arousal, more pleasantness, and more sense of control compared with loaded SDB.

\section{\begin{tabular}{l|l}
2 & METHOD
\end{tabular}}

\section{1 | Participants}

This experimental study was conducted in the human psychophysiology laboratory of the Health Psychology Research Group, KU Leuven (Leuven, Belgium). Healthy volunteers aged 18 to 45 years were invited. Those who reported any of the following conditions were not included in the study: cardiovascular, respiratory, or neurological diseases, acute or chronic pain conditions, psychiatric disorders, regular medication use other than contraceptives, pregnancy, current smoking, or any other nicotine consumption, and regular practice of a breathing exercise. Also, those with body mass index of $<18.5$ or $>30 \mathrm{~kg} / \mathrm{m}^{2}$, a score of $\geq 8$ (indicating considerable symptoms) in any of the two subscales of the Hospital Anxiety and Depression Scale (Bjelland et al., 2002), and moderate or higher levels of nasal symptoms in the Nasal Obstruction Symptom Evaluation scale (Stewart et al., 2004) were not included. ${ }^{2}$ Participants were asked to refrain from strenuous exercise as well as caffeine and alcohol intake for at least $12 \mathrm{hr}$ before testing. The study was approved by the Medical Ethics Committee Research UZ/KU Leuven (\#S61356), and written informed consent was obtained from the participants. The study was performed in a single 2-hr session, between 9 a.m. and 5 p.m., in a sound-attenuated and temperature-controlled $\left(22-25^{\circ} \mathrm{C}\right)$ room.

\subsection{Instruments and measurements}

\subsection{1 | Respiratory measures}

Respiratory (chest) movement was recorded using a chest bellows connected to a transducer coupler (V94-19, V9405, V72-25B, Coulbourn Instruments, PA, US). It was secured with the attached chain around the upper abdomen,

\footnotetext{
${ }^{2} \mathrm{~A}$ Dutch version of the questionnaires was used for Dutch speaking participants; (Spinhoven et al., 1997; van Zijl et al., 2017).
}

adjacent to the lower thoracic ribs' region. To estimate tidal volume, the respiratory movement signal was calibrated against a pneumotachometer. Participants breathed through the mouth for $2 \mathrm{~min}$ and used a nose clip and a disposable filter with an integrated oval shaped mouthpiece (MicroGard II Pulmonary Function Filter, Carefusion, Höchberg, Germany) connected to a pneumotachometer (4,813, Hans Rudolph Inc., Shawnee, US) and a pressure transducer and amplifier (series 1,110, Hans Rudolph Inc., Shawnee, US). To have a range of different tidal volumes over the respiratory cycles, participants were asked to breathe in the following order: $30 \mathrm{~s}$ normal breathing, $60 \mathrm{~s}$ slow and deep breathing, $30 \mathrm{~s}$ normal breathing. The average correlation coefficient between the amplitudes of the respiratory movements and tidal volumes in the cycles was 0.96 [95\% confidence interval, 0.94 to 0.97 ].

\subsection{2 | Inspiratory threshold load}

The flow-independent threshold load (Threshold PEP, Respironics Inc., NJ, US) was used and set to a load of $10 \mathrm{cmH}_{2} \mathrm{O}$ based on our previous study (Gholamrezaei et al., 2019). A nose clip was used to help the participant to breathe only through the mouth during loaded SDB.

\subsection{3 | Electrocardiography and blood pressure}

The electrocardiography signal was recorded in lead II configuration (right and left mid-clavicle and lower left rib cage) using disposable electrodes (H66LG, Kendall ${ }^{\mathrm{TM}}$, Covidien LLC, MA, US). Analog amplification (gain $1 \mathrm{~K}$ ) and bandpass filtering $(0.1$ to $150 \mathrm{~Hz})$ was performed by the isolated bio-amplifier (V75-04, Coulbourn Instruments, Allentown, PA, US). Continuous non-invasive arterial pressure was measured at the middle or ring finger of the left hand using the volume clamp method (Portapres Model-2, TNO TPD Biomedical Instrumentation, Amsterdam, the Netherlands). A cuff with appropriate size was attached to the middle phalanx of the middle or ring finger of the left hand. The servo-reset mode (PhysioCal) was active before each test, permitting multiple automatic auto-calibrations, but it was inactive during the actual test to avoid missing data. Arm blood pressure was measured using an automatic sphygmomanometer which utilizes the oscillometric method (Kodea KD-202F, Shanghai Kodea Economic \& Trade Development Co., Ltd., Shanghai, China).

All signals were recorded and digitized at $1 \mathrm{KHz}$ sampling rate (16-bit PCI-6221 card, National Instruments, Texas, USA) using AFFECT software version 4.0 (KU Leuven, Belgium) (Spruyt et al., 2010). 


\subsection{4 | Self-reported measurements}

Considering that participants (especially novices) may experience dyspnea during slow breathing (Allen \& Friedman, 2012; Szulczewski, 2019) and particularly during loaded SDB (Gholamrezaei et al., 2019), dyspnea (phrased as "difficulty in breathing") was measured using the modified Borg scale with scores ranging from 0 (nothing at all) to 10 (intolerable) (Borg, 1982). Emotional responses were assessed in three dimensions of arousal, valence, and dominance using the 9-point Self-Assessment Manikin scale. Responses were later scored from 1 (extreme calm/pleasant/ lack of control) to 9 (extreme excited/unpleasant/control) (Bradley \& Lang, 1994). Possible adverse events were assessed at the end of the study using a checklist of symptoms (e.g., dizziness, sleepiness, and cough) and were rated as mild, moderate, or severe.

\section{3 | Procedures}

\subsection{1 | Baseline measures}

Participants were seated in a comfortable chair with the upper body and arms being supported. After the equipment and electrodes were attached, participants rested for $5 \mathrm{~min}$. This period was included as the resting baseline physiological state. Arm blood pressure was measured two times at the end of this baseline period.

\subsection{2 | Training}

First, participants were trained to perform controlled breathing (also known as paced breathing) at different breathing frequencies. Using the AFFECT software version 4.0 (KU Leuven, Belgium) (Spruyt et al., 2010), a visual cue (vertical bar) was continuously presented on a computer screen. Participants practiced breathing at a frequency of $0.23 \mathrm{~Hz}$ (14 breaths per minute) and $0.1 \mathrm{~Hz}$ (6 breaths per minute). The inspiration to expiration ratio was $1: 2$. These parameters were selected based on several other studies (for review see Russo et al., 2017) including those in our laboratory (for example see Courtois et al., 2019; Gholamrezaei et al., 2019; Jafari et al., 2020; Van Diest et al., 2014). Participants practiced each breathing frequency for $2 \mathrm{~min}$. At the beginning of each breathing condition, participants received relevant instructions. For the PLB technique, participants were instructed to breathe in through the nose and breathe out through the mouth while pursing the lips (Spahija \& Grassino, 1996). For the UNB technique, participants were instructed to use the thumb of their right hand to close the right and left nostrils for LUNB and RUNB, respectively (Jella \& Shannahoff-Khalsa, 1993).
For the loaded SDB technique, participants were instructed to breathe deeply to open the load valve and keep it open during inspiration (Gholamrezaei et al., 2019). In all conditions, and to prevent hyperventilation, participants were instructed to always breathe comfortably, without extra effort.

The instructor demonstrated how to perform each of the breathing conditions. Participants practiced each condition for $1 \mathrm{~min}$ with the visual cue (set at $0.1 \mathrm{~Hz}$ ) on the monitor. After each practice run, they rated their breathing on dyspnea, valence, arousal, and dominance (also to practice ratings). If dyspnea with ITL of $10 \mathrm{cmH}_{2} \mathrm{O}$ was rated as equal to or higher than moderate on the Borg scale, the load was reduced to $5 \mathrm{cmH}_{2} \mathrm{O}$ for the main test (Gholamrezaei et al., 2019).

\subsection{3 | Main test}

The main test included four controlled breathing conditions: PLB, LUNB, RUNB, and loaded SDB. Each condition lasted 3 min considering the feasibility of the loaded SDB (Gholamrezaei et al., 2019). The frequency of breathing was set at $0.1 \mathrm{~Hz}$ for all conditions. The order of the conditions was counterbalanced and randomized for participants using the Research Randomizer (www.randomizer.org). We did not include uncontrolled breathing and/or controlled breathing at normal frequency conditions in the main test since previous studies, including ours (Gholamrezaei et al., 2019), have already reported the psychophysiological effects of SDB compared to such controls (for review see Russo et al., 2017).

The physiological signals were continuously recorded during the breathing conditions. Following each condition, participants rated dyspnea, as well as their emotional state on the valence, arousal, and dominance dimensions. There were 5-min rest periods between the training and the main test as well between the breathing conditions to prevent the carryover effect.

\subsection{Data reduction and analysis}

All physiological signals were processed using customwritten algorithms in MATLAB software (R2018b, Mathworks, Inc., Natick, MA). The respiratory signal was passed through a first-order Butterworth low-pass filter with a cutoff frequency of $1 \mathrm{~Hz}$ to remove high-frequency noise. Respiratory cycles were identified using the peak detection method. The amplitudes of the respiratory cycles were measured using the peak-to-valley method. Cycles were visually inspected, and the inspiratory/expiratory points were manually corrected if needed. If the correction was not possible due to extreme noise, the cycle was excluded from statistical analysis. The estimated tidal volume was measured as explained above. Estimated 
minute ventilation was calculated as estimated tidal volume $\times$ breathing frequency.

The electrocardiography signal was further passed through a first-order Butterworth high-pass filter with a cutoff frequency of $1 \mathrm{~Hz}$ to remove baseline wander artifacts. The times of R-wave peaks were determined in the electrocardiography signal using the peak detection method and RRintervals were calculated. The arterial pressure wave signal was passed through a first-order Butterworth low-pass filter with a cutoff frequency of $30 \mathrm{~Hz}$ to remove high-frequency noise. The arterial pressure signal was then aligned with the R-wave peak time series for extracting systolic and diastolic blood pressure values. With this method, we ensured that for each heartbeat from the electrocardiography signal there are corresponding blood pressure values. Systolic and diastolic blood pressure values were extracted from the arterial pressure wave signal using the peak and valley method (Gholamrezaei et al., 2019).

Analysis of heart rate variability (HRV) was performed according to available guidelines (Task Force of the European Society of Cardiology \& the North American Society of Pacing \& Electrophysiology, 1996). Average of RR-intervals (representing tonic autonomic activity) and root mean square of the successive differences (RMSSD) (representing vagally mediated HRV) were calculated for each breathing condition. We chose these measures since the duration of each breathing condition was $3 \mathrm{~min}$ which is proper for time-domain (Melo et al., 2018) but not optimal for frequency-domain HRV indices. Also, RSA (representing respiratory modulation of cardiac vagal activity) and the amplitude of systolic blood pressure variation (BPV) were calculated for each respiratory cycle with the peak-to-valley method, and then, were averaged for each breathing condition (Gholamrezaei et al., 2019). Averages of systolic and diastolic blood pressure were also calculated for each breathing condition. To explore the effect of different breathing techniques on cardiorespiratory dynamics, we visualized the respiratory signal and systolic blood pressure and RR-interval time series over respiratory cycles in each condition based on the pattern analysis method (Gholamrezaei et al., 2019; Sin et al., 2010). Power spectral analysis (Burg's method) was performed on the respiratory signal and on the RR-interval and systolic blood pressure time series for visualization purposes only. To do this, the respiratory signal was resampled at $4 \mathrm{~Hz}$. The blood pressure and RR-intervals time series were resampled at $4 \mathrm{~Hz}$ after cubic spline interpolation. Very-low-frequency components were removed using a high pass filter (cutoff $0.015 \mathrm{~Hz}$ ) (Gholamrezaei et al., 2019).

Cardiovagal BRS, defined as the change in RR-intervals (in msec) per unit change in blood pressure, was calculated using the sequence method (Parati et al., 1988). The following criteria were applied to find "effective" baroreflex sequences: $\geq 1 \mathrm{mmHg}$ change in successive systolic blood pressures, $\geq 5$ msec change in successive RR-intervals, $\geq 3$ heartbeats in each sequence, $\geq 0.8$ coefficient of correlation between changes in systolic blood pressures and RR-intervals, and one beat lag (delay) between systolic blood pressure and RR-interval time series. We only analyzed the up sequences (parallel increase in systolic blood pressures and RR intervals) since such sequences represent stimulation of the arterial baroreceptors. The BRS was averaged over the sequences in each breathing condition. We also calculated the baroreflex effectiveness index (BEI) as the number of effective up-sequences divided by the total number of systolic blood pressure up-ramps.

All data were visually inspected and corrected. If the manual correction was not possible or in the case of an ectopic beat, the beat was marked as an artifact. For time-domain indexes of HRV, "deletion" was used for managing artifacts as this method is associated with less bias than other interpolation methods (Rincon Soler et al., 2017). Regarding RSA and $\mathrm{BPV}$, the measure was excluded without interpolation if the peak or valley points contained artifacts.

\section{5 | Statistical analyses}

The required sample size to detect an effect size (Cohen's $f$ ) of 0.25 (Gholamrezaei et al., 2019) using repeated measure ANOVAs with a power of 0.9 and alpha (type I error) of 0.05 , and an expected $10 \%$ missing data due to technical failures, was calculated as 35 using the G*Power software (Düsseldorf, Germany) (Faul et al., 2007).

The study primary outcomes were the BPV and HRV indices. Secondary outcomes included respiratory and baroreflex measures and the reported dyspnea, valence, arousal, and dominance. Marginal linear mixed models with the breathing condition as a within-subject factor were performed. Pairwise contrasts were performed wherever the effect of breathing condition was significant. The Holm-Bonferroni (stepdown) method was applied for correcting $p$ values for multiple comparisons (Holm, 1979). According to our previous study (Gholamrezaei et al., 2019), we performed separate mediation analyses to test whether the effect of breathing condition on RSA was mediated via alterations in BPV and/ or estimated tidal volume. To do this, the independent (and total) effects of the independent variables and of the potential mediators on the outcomes as well as the effect of independent variables on the potential mediators were tested in separate marginal mixed models.

Statistical significance was set at $p<.05$ for all analyses. Data are reported as least-squares means with standard error. Contrasts with a significant result are mentioned in the main text. Detailed results of the pairwise contrasts are mentioned in the supplementary material with data presented as differences of the least-squares means and standard error. 
Statistical analyses were performed using SAS® Studio 3.8 (SAS Institute Inc., Cary, NC, US).

\section{3 | RESULTS}

\section{1 | Participants}

From a total of 104 volunteers, 35 were eligible to participate. Reasons for not including volunteers were as follows: having considerable anxiety/depression symptoms (i.e., score of $\geq 8$ in any of the two subscales of the Hospital Anxiety and Depression Scale, $N=29$ ), body mass index of $<18.5$ or $>30 \mathrm{~kg} / \mathrm{m}^{2}$ $(N=13)$, and moderate or higher levels of nasal symptoms $(N=27)$. Study participants included 20 females and 15 males with a mean ( \pm standard deviation) age of $21 \pm 4$ years (range: 18-32). The demographic and baseline characteristics of the participants are summarized in Table 1. Three participants rated dyspnea at or above the moderate level for breathing with a load of $10 \mathrm{cmH}_{2} \mathrm{O}$ during the training phase and the load was reduced to $5 \mathrm{cmH}_{2} \mathrm{O}$ for these participants.

\section{2 | Respiration measures and manipulation check}

All participants were able to alter their breathing rate to $\sim 6$ breaths per minute (i.e., $\sim 0.1 \mathrm{~Hz}$ ); Table 2, Figure S1a. Compared to a tidal volume of $\sim 0.5 \mathrm{~L}$ during baseline, the

TA BLE 1 Demographic data and baseline characteristics

\begin{tabular}{|ll|}
\hline & $N=35$ \\
\hline Female/Male & $20(57.1) / 15(42.8)$ \\
\hline Age $($ year $)$ & $21.7 \pm 4.0$ \\
\hline $\mathrm{BMI}\left(\mathrm{kg} / \mathrm{m}^{2}\right)$ & $21.6 \pm 2.3$ \\
\hline Baseline measures & \\
\hline $\mathrm{BR}($ breath/minute $)$ & $14.6 \pm 3.9$ \\
$e \mathrm{~V}_{\mathrm{T}}(\mathrm{L})$ & $0.5 \pm 0.3$ \\
\hline$e \mathrm{~V}_{\mathrm{E}}(\mathrm{L})$ & $7.4 \pm 3.0$ \\
\hline $\mathrm{RR}-\mathrm{interval}(\mathrm{msec})$ & $841.2 \pm 143.0$ \\
\hline $\mathrm{RMSSD}(\mathrm{msec})$ & $39.5 \pm 21.2$ \\
\hline $\mathrm{SBP}(\mathrm{mmHg})^{\mathrm{a}}$ & $109.7 \pm 8.9$ \\
\hline $\mathrm{DBP}(\mathrm{mmHg})^{\mathrm{a}}$ & $71.7 \pm 5.5$ \\
\hline $\mathrm{BRS}(\mathrm{msec} / \mathrm{mmHg})$ & $11.8 \pm 6.1$ \\
\hline $\mathrm{BEI}$ & $0.7 \pm 0.1$ \\
\hline
\end{tabular}

Notes: Data are presented as mean \pm standard deviation or number $(\%)$.

Abbreviations: BEI, baroreflex effectiveness index; BMI, body mass index; BR, breathing rate; $\mathrm{BRS}$, baroreflex sensitivity; $\mathrm{DBP}$, diastolic blood pressure; $e \mathrm{~V}_{\mathrm{E}}$, estimated minute ventilation; $e \mathrm{~V}_{\mathrm{T}}$, estimated tidal volume; RMSSD, root mean square of successive differences; SBP, systolic blood pressure.

${ }^{\text {a}}$ Measured at the arm. estimated tidal volume was between 1.2 and 1.4 liter in the four breathing conditions indicating that participants increased their breathing depth. The effects of breathing condition on tidal volume and minute ventilation were significant $(p<.001)$. Tidal volume and minute ventilation were higher during loaded SDB compared to LUNB and RUNB. They were also higher during PLB compared to LUNB (Tables 2, $\mathrm{S} 1$ and S2).

\section{3 | Blood pressure measures}

The effects of breathing condition on the average systolic $(p=.034)$ and diastolic blood pressure $(p=.001)$ and BPV $(p<.001)$ were significant (Table 3$)$. Pairwise contrasts showed that systolic blood pressure was lower during PLB compared to RUNB (Table S3). The average diastolic blood pressure was lower during PLB compared to LUNB/ RUNB (Tables 3 and S4). Blood pressure variability was concentrated in the low-frequency band around $\sim 0.1 \mathrm{~Hz}$ in all breathing conditions (Figure S1b). The amplitude of BPV was higher during loaded SDB compared to the other conditions, and higher during PLB compared to LUNB/ RUNB (Tables 3 and S5).

\section{$3.4 \quad$ Heart rate measures}

The effect of breathing condition on mean RR-interval was not significant $(p=.736)$. Heart rate variability was concentrated in the low-frequency band around $\sim 0.1 \mathrm{~Hz}$ in all the breathing conditions (Figure S1c). There were significant effects of breathing condition on RMSSD $(p<.001)$ and RSA $(p<.001)$. Pairwise contrasts showed that RMSSD and RSA were higher during loaded SDB compared to the other conditions. There were also higher during PLB compared to LUNB (Tables 4, S6 and S7).

\section{5 | Baroreflex function}

On average, there were $18.3 \pm 2.1$ systolic blood pressure upramps and $15.5 \pm 3.6$ effective up-sequences in each of the breathing conditions. The effects of the breathing condition on BRS and BEI were not significant (Table 5).

\section{6 | Pattern analysis}

The 1st derivative of the respiratory signal can be considered as a surrogate measure for tracking respiratory airflow. Participants tended to have lower inspiratory airflow during LUNB/RUNB versus loaded SDB and PLB (Figure 1). 
T A B L E 2 Means (standard error) of respiratory parameters between the breathing conditions

\begin{tabular}{|c|c|c|c|c|c|c|}
\hline & Loaded SDB & LUNB & RUNB & PLB & Main effect & Contrasts* \\
\hline$e \mathrm{~V}_{\mathrm{T}}(\mathrm{L})$ & $1.4(0.09)$ & $1.2(0.09)$ & $1.2(0.08)$ & $1.3(0.08)$ & $F=9.33, p<.001$ & $\begin{array}{l}\text { Loaded SDB vs. LUNB } \\
\text { Loaded SDB vs. RUNB } \\
\text { PLB vs. LUNB }\end{array}$ \\
\hline$e \mathrm{~V}_{\mathrm{E}}(\mathrm{L})$ & $8.8(0.5)$ & $7.2(0.5)$ & $7.4(0.5)$ & $8.2(0.5)$ & $F=9.31, p<.001$ & $\begin{array}{l}\text { Loaded SDB vs. LUNB } \\
\text { Loaded SDB vs. RUNB } \\
\text { PLB vs. LUNB }\end{array}$ \\
\hline
\end{tabular}

Abbreviations: $\mathrm{BR}$, breathing rate; $e \mathrm{~V}_{\mathrm{E}}$, estimated minute ventilation; $e \mathrm{~V}_{\mathrm{T}}$, estimated tidal volume; LUNB, left unilateral nostril breathing; PLB, pursed-lips breathing; RUNB, right unilateral nostril breathing; SDB, slow deep breathing.

*Only significant contrasts are listed, ${ }^{\dagger} p<.001 ;{ }^{\ddagger} p<.01 ;{ }^{\ddagger} p<.05$.

TA B L E 3 Means (standard error) of blood pressure (variability) parameters between the breathing conditions

\begin{tabular}{|c|c|c|c|c|c|c|}
\hline & $\begin{array}{l}\text { Loaded } \\
\text { SDB }\end{array}$ & LUNB & RUNB & PLB & Main effect & Contrasts* \\
\hline $\mathrm{SBP}(\mathrm{mmHg})$ & $135.0(2.2)$ & $135.8(2.3)$ & $136.7(2.2)$ & $132.2(2.5)$ & $F=3.23, p=.034$ & RUNB vs. PLB ${ }^{¥}$ \\
\hline $\mathrm{DBP}(\mathrm{mmHg})$ & & & & & & RUNB vs. PLB \\
\hline \multirow[t]{4}{*}{$\mathrm{BPV}(\mathrm{mmHg})$} & $25.9(1.3)$ & $19.4(1.0)$ & $19.7(0.9)$ & $23.4(1.3)$ & $F=18.45, p<.001$ & Loaded SDB vs. LUNB ${ }^{\dagger}$ \\
\hline & & & & & & Loaded SDB vs. PLB ${ }^{¥}$ \\
\hline & & & & & & PLB vs. LUNB ${ }^{\dagger}$ \\
\hline & & & & & & PLB vs. RUNB \\
\hline
\end{tabular}

Note: Values are arterial pressure measured at the finger.

Abbreviations: BPV, amplitude of systolic blood pressure variation; DBP, diastolic blood pressure; LUNB, left unilateral nostril breathing; PLB, pursed-lips breathing; RUNB, right unilateral nostril breathing; SBP, systolic blood pressure; SDB, slow deep breathing.

*Only significant contrasts are listed, ${ }^{\dagger} p<.001,{ }^{\ddagger} p<.01,{ }^{\ddagger} p<.05$.

Loaded SDB and PLB were associated with greater drops in systolic blood pressure and RR-interval during inspiration compared to LUNB/RUNB. Loaded SDB was associated with higher RR-intervals during expiration compared to the other conditions, which was in line with the effect on RSA (Table 4). Changes from nadir to peak were also steeper for both systolic blood pressure and RR-interval in the loaded SDB compared to the other conditions (see the 1st derivatives in Figure 1). Of note, the patterns of systolic blood pressure and RR-interval over the respiratory cycle were very similar between LUNB and RUNB.

\section{7 | Dyspnea, valence, arousal, and dominance ratings}

The effect of breathing condition on dyspnea was significant ( $p=.014$, Table S8). Participants reported higher levels of dyspnea during loaded SDB compared to LUNB and PLB (Figure 2a, Table S9). The effects of breathing condition on arousal, valence, and dominance were also significant (all $p$ values $<0.001$, Table S8). Participants reported more arousal during loaded SDB and lower arousal during PLB compared to other conditions (Figure 2b, Table S10). They rated loaded SDB as less pleasant and PLB as more pleasant compared to other conditions (Figure 2c, Table S11). Sense of control was lower during loaded SDB and higher during PLB compared to other conditions (Figure 2d, Table S12).

\section{8 | Exploring the mechanisms underlying the effect of breathing condition on respiratory sinus arrhythmia}

Three measured factors could potentially mediate the effect of breathing condition on RSA: 1) increased BPV amplitude over the respiratory cycles which can contribute to increased RSA due to enhanced stimulation of the arterial baroreceptors and via the arterial baroreflex (Karemaker, 2009), 2) increased baroreflex sensitivity and/or effectiveness, and 3) 
TA B L E 4 Mean (standard error) of heart rate variability parameters between the breathing conditions

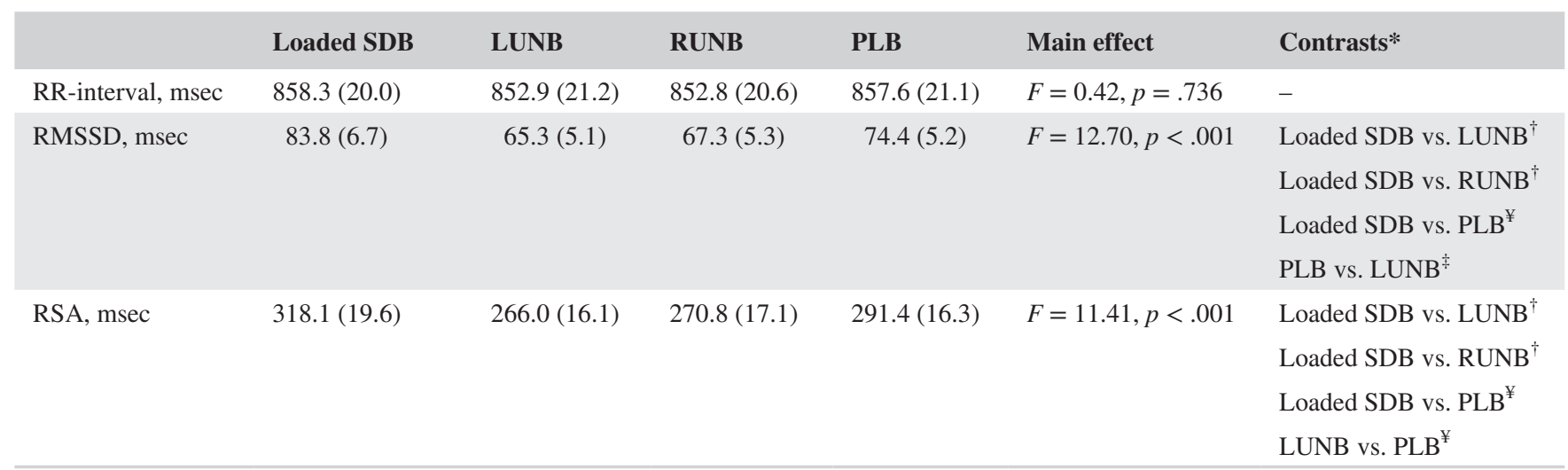

Abbreviations: LUNB, left unilateral nostril breathing; PLB, pursed-lips breathing; RMSSD, root mean square of successive differences; RSA, respiratory sinus arrhythmia; RUNB, right unilateral nostril breathing; SDB, slow deep breathing.

*Only significant contrasts are listed, ${ }^{\dagger} p<.001,{ }^{\ddagger} p<.01,{ }^{\ddagger} p<.05$.

TA B L E 5 Mean (standard error) of baroreflex function between the breathing conditions

\begin{tabular}{|lcccccc} 
& Loaded SDB & LUNB & RUNB & PLB & Main effect & Contrasts* \\
BRS (msec/mmHg) & $18.8(1.0)$ & $19.1(1.1)$ & $18.6(1.1)$ & $17.8(1.2)$ & $F=0.41, p=.749$ \\
BEI & $0.8(0.03)$ & $0.8(0.04)$ & $0.8(0.03)$ & $0.8(0.03)$ & $F=0.54, p=.656$ \\
\hline
\end{tabular}

Abbreviations: BEI, baroreflex effectiveness index; BRS, baroreflex sensitivity; LUNB, left unilateral nostril breathing; PLB, pursed-lips breathing; RUNB, right unilateral nostril breathing; SDB, slow deep breathing.

*There was no significant contrast to be listed.

increased tidal volume which can contribute to RSA via nonbaroreflex mechanisms such as stimulation of the pulmonary vagal afferents (Taha et al., 1995). Since there was no difference between the breathing conditions in baroreflex sensitivity or effectiveness, we only included BPV and tidal volume in the models as potential mediators.

The effect of breathing condition on RSA (Figure 3, Model B) was no longer significant after including BPV into the model (Figure 3, Model C). The effect of breathing condition on RSA remained significant after including tidal volume into the model, while there was no association between tidal volume and RSA, controlling for the effect of breathing condition (Figure 3, Model D). Since RR-interval can influence systolic blood pressure via feed-forward mechanisms (via ventricular filling and preload) (Schulz et al., 2013), we repeated the mediation analysis with RSA as the possible mediator and BPV as the dependent variable. The effect of breathing condition on BPV was not mediated by RSA (Figure S2).

\section{9 | Adverse events}

The frequency of the reported adverse events was as follows; dizziness $(N=6)$, sleepiness $(N=2)$, cough $(N=1)$, and nausea $(N=1)$. Coughing was observed only during loaded SDB and nausea was attributed by the participant to the mouthpiece during loaded SDB. For the other adverse events, we did not specifically ask for which condition the event has been experienced. All adverse events were rated as mild with all participants and resolved at the end of the study.

\section{4 | DISCUSSION}

The present experiment aimed to investigate possible differences between four SDB techniques regarding their effects on cardiovascular parameters and emotional state. We will discuss such effects and address our priori hypotheses in separate subheadings as follows.

\section{1 | Respiratory measures}

An interesting finding of this study was that, although participants increased their tidal volume during all SDB techniques, they tended to have lower tidal volume during UNB relative to other techniques. Breathing via one nostril is similar to adding a resistive load on respiration (Pallanch et al., 1985). Since the perceived magnitude of a resistive load depends on the airflow (Killian et al., 1982), participants might have reduced their airflow during UNB to decrease the perceived feeling of resistance. Notably, the relatively lower airflow 
FIGURE 1 Pattern analysis of respiratory signal (RSP), systolic blood pressure (SBP), and RR-interval (RRI) over the respiratory cycle between the breathing conditions; loaded SDB (ITL), left and right unilateral nostril breathing (LUNB, RUNB), and pursed-lips breathing (PLB). Data are averaged across all respiratory cycles for each condition/participant, and then, averaged across all participants. The right column includes the 1 st derivatives of the signals

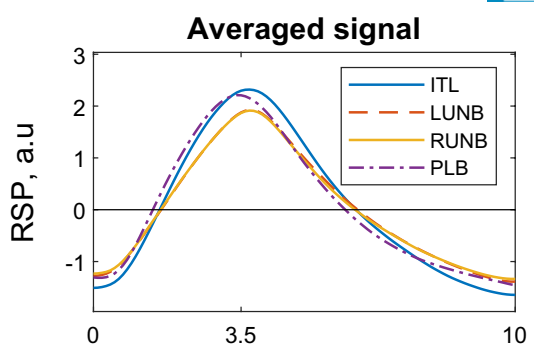

1st derivative
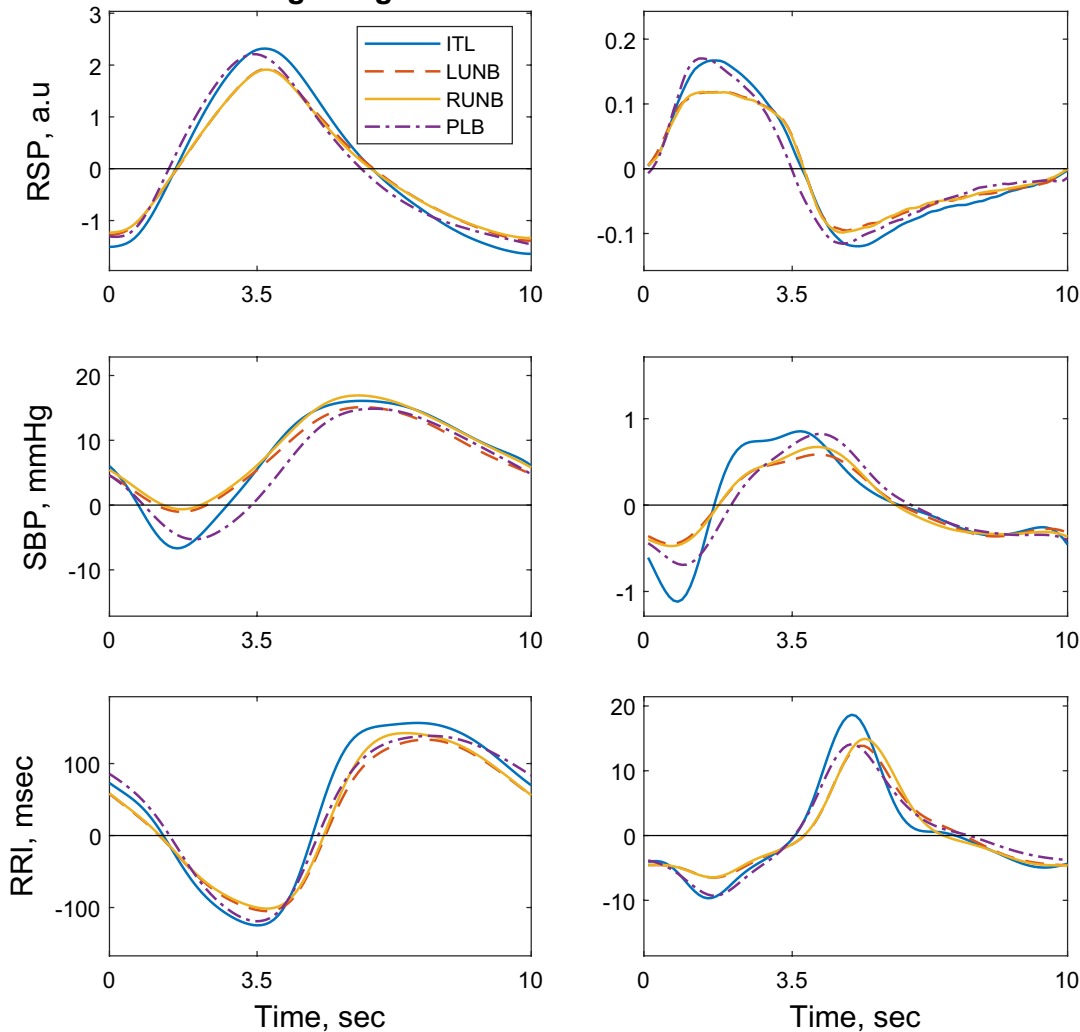

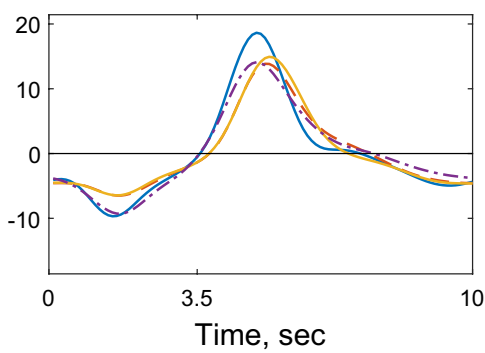

(tidal volume) during UNB does not seem to disrupt the ventilation as minute ventilation was not different between the resting baseline period and UNB (see Table S13). This effect may even be beneficial by reducing the risk of hyperventilation during SDB exercise (Szulczewski, 2019), particularly with the loaded SDB technique as it was associated with the highest minute ventilation among other techniques in this study.

\section{2 | Cardiovascular measures}

Overall, average blood pressure was lower during PLB which may indicate a lower vascular sympathetic tone with this breathing technique (Mancia \& Grassi, 2014), although no measure of sympathetic activity was included to consolidate this interpretation. This result should be interpreted cautiously as the expiratory resistance might be different between the breathing conditions which could potentially influence venous return (Fessler et al., 1992). Using specific measures of sympathetic activity (e.g., muscle sympathetic nerve activity) (Macefield \& Henderson, 2019) can be helpful to better investigate the mechanisms underlying the influence of different SDB techniques on systemic blood pressure.

In our study, the variation of systolic blood pressure over the respiratory cycle was highest for the loaded SDB condition, which is in line with our previous findings (Gholamrezaei et al., 2019). This can be due to the mechanical effects of respiration (and intrathoracic pressure) on ventricular stroke volume (Elstad et al., 2018). The type of respiratory load (threshold, resistive), as well as the respiratory phase during which the load was present (inspiratory during loaded SDB, inspiratory/expiratory during UNB), were not the same between the breathing conditions. Therefore, we can expect different effects of these breathing techniques on ventricular stroke volume and its determinants (ventricular preload and afterload) (Lalande et al., 2012). This requires further investigation using proper cardiac imaging methods (e.g., echocardiography or real-time cardiac magnetic resonance).

Contrary to our hypothesis, we found that BPV was lower during UNB compared to PLB, which may be due to a less variation in intrathoracic pressure during UNB as explained above. Mediation analyses showed that differences in RSA between the SDB techniques were associated with changes in BPV, but not tidal volume. In the absence of a difference between the SDB techniques in baroreflex sensitivity or effectiveness, this result suggests enhanced stimulation of the arterial baroreceptors during loaded SDB and PLB (vs. UNB) because of larger blood pressure variation as the possible underlying mechanism (Gholamrezaei et al., 2019). However, increased RSA during loaded SDB and PLB (vs. UNB) was not accompanied by a lower average heart rate. This highlights the distinction between respiratory modulation of cardiac vagal activity (i.e., RSA), which is a phasic response during 

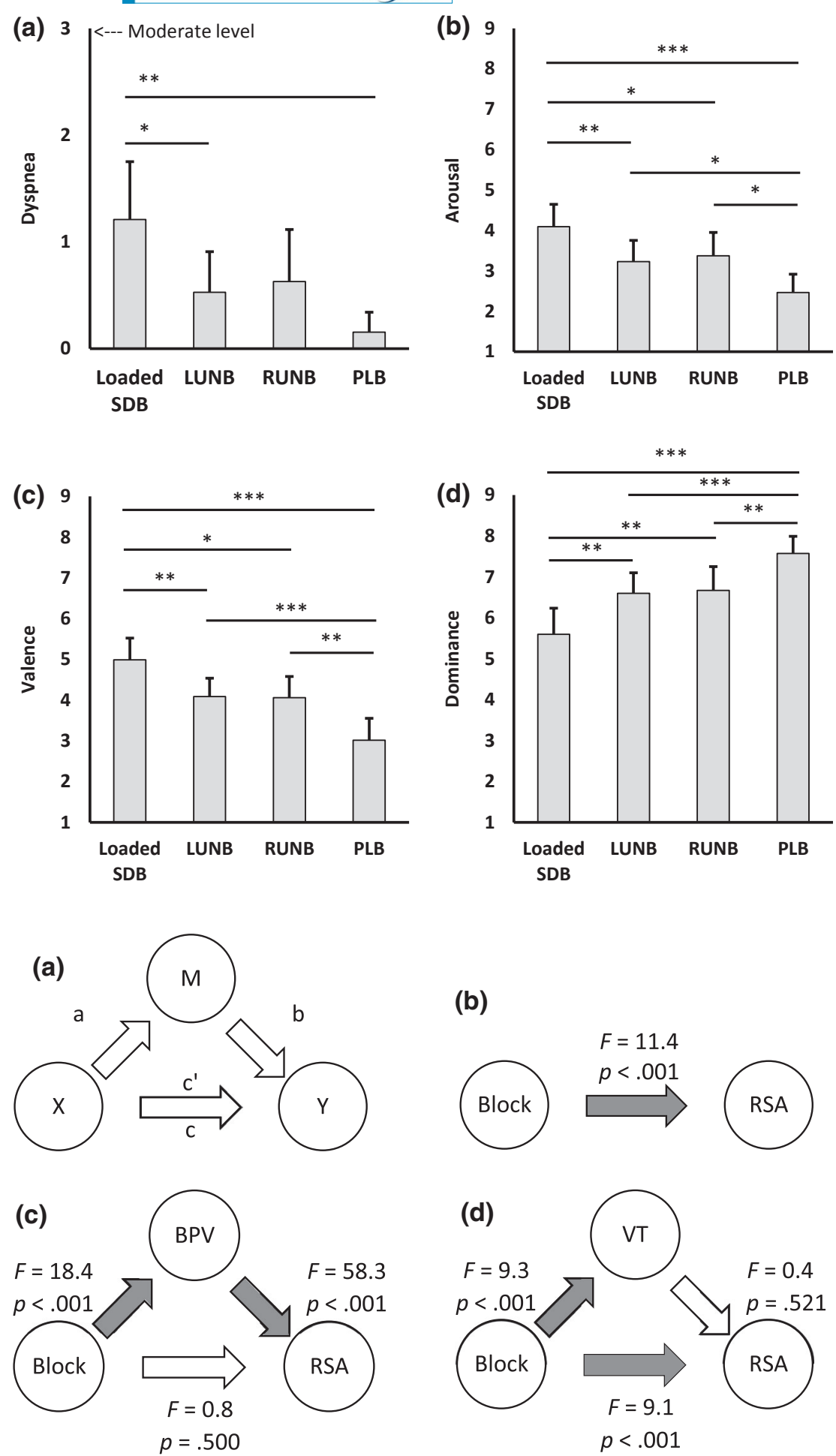

(b)

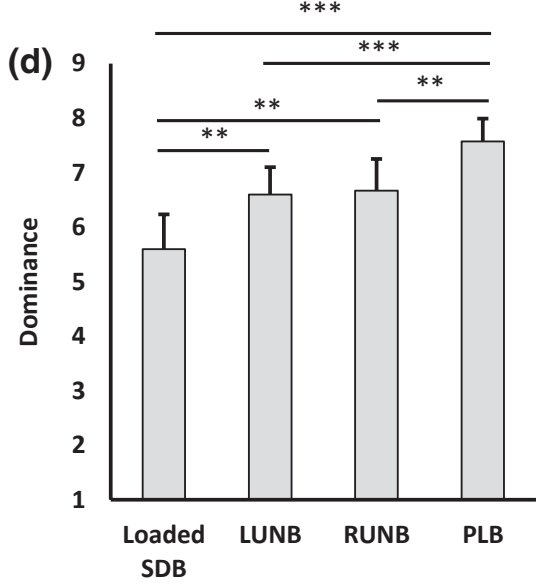

F IG URE 3 Mediation analysis. X: independent variable, Y: dependent variable, M: mediator, a: $\mathrm{X}->\mathrm{M}$ relationship, $\mathrm{b}$ : $\mathrm{M}->\mathrm{Y}$ relationship, $c^{\prime}$ : unmediated $\mathrm{X}->\mathrm{Y}$ relationship (residual), c: $\mathrm{X}$-> $\mathrm{Y}$ relationship (model 3A). Examining the effect of breathing condition (block) on respiratory sinus arrhythmia (RSA) (model B), having the amplitude of systolic blood pressure variation (BPV) as the mediator (model C), and having estimated tidal volume $\left(V_{T}\right)$ as the mediator (model D)
SDB, and the cardiac vagal tone (Farmer et al., 2016). Although a study using sympathetic and parasympathetic (vagal) blockades has shown that alterations in HRV in response to SDB mainly represent cardiac vagal modulation (Kromenacker et al., 2018), we cannot rule out a potential role of differential sympathetic modulation in the generation of RSA in response to different SDB techniques in our study (see also Taylor et al., 2001). This would require measuring sympathetic activity (e.g., with muscle sympathetic nerve activity) or pharmacological blockade of the autonomic activity and warrants further investigation.

Several studies have shown that (spontaneous) baroreflex sensitivity and effectiveness increases during SDB compared to uncontrolled breathing or controlled breathing at normal breathing frequency (Courtois et al., 2019; Gholamrezaei et al., 2019; Jafari et al., 2020; Joseph et al., 2005; Lehrer 
et al., 2003; Wang et al., 2013). We found no difference between the SDB techniques in baroreflex sensitivity or effectiveness which may be due to a ceiling effect. It must be noted that the increased RSA during SDB may be due to both baroreflex and non-baroreflex mediating mechanisms (e.g., myocardial stretch, increased tidal volume) (Elstad et al., 2018; Taylor et al., 2001). Also, the sequence method may overestimate the BRS during SDB due to superimposing of heart rate and blood pressure variability on $0.1 \mathrm{~Hz}$ rhythm (Tzeng et al., 2009). In this regard, an experimental study found no difference between controlled breathing at normal $(0.25 \mathrm{~Hz})$ and slow $(0.1 \mathrm{~Hz})$ frequencies in BRS when it was measured with the classical Oxford method which utilizes pharmacologically induced baroreceptors stimulation across a wide range of blood pressures (Tzeng et al., 2009). It is warranted to test the effect of various SDB techniques on BRS using other methods such as the Oxford method (Tzeng et al., 2009).

\section{3 $\quad$ Dyspnea and emotional measures}

Although loaded SDB was associated with the highest dyspnea ratings, only for 3 subjects it was required to reduce the load to $5 \mathrm{cmH}_{2} \mathrm{O}$. Slow, deep breathing particularly with low inspiration to expiration ratio, can induce a relaxed state (Van Diest et al., 2014) and reduce physiological and/or psychological arousal in response to a threat, such as pain anticipation (Cappo \& Holmes, 1984; McCaul et al., 1979; Sakakibara \& Hayano, 1996). In the current study, PLB was associated with favorable emotional responses (lower arousal, higher pleasantness, higher perceived control) compared to other SDB techniques. We did not include volunteers with a high level of anxiety and the study context was not threatening. The emotional responses to different SDB techniques may better be evaluated in a threat context and also in people with higher levels of anxiety/stress.

\section{4 | Left, or right nasal breathing?}

It is reported that RUNB increases while LUNB decreases heart rate and blood pressure suggesting sympathetic and parasympathetic stimulation, respectively (Raghuraj \& Telles, 2008; Shannahoff-Khalsa \& Kennedy, 1993). The mechanism for such differential effects is not clear yet. Nasal breathing rhythms not only influence the limbic activity but also can modulate the oscillatory patterns throughout the brain (Zelano et al., 2016). Considering some evidence on the asymmetry in the central autonomic nervous system (McGinley \& Friedman, 2015), LUNB and RUNB may differentially influence autonomic activity at the central level. In contrast to previous studies, we found no differential effect between LUNB and RUNB on cardiac autonomic activity. This may be due to a shorter duration of the breathing exercise in our study ( $3 \mathrm{~min}$ ) compared with the previous studies (15 to $30 \mathrm{~min}$ ) (Jella \& Shannahoff-Khalsa, 1993; Raghuraj \& Telles, 2008; Shannahoff-Khalsa \& Kennedy, 1993).

\section{5 | Implications}

Slow, deep breathing has been shown by several studies to reduce blood pressure and heart rate in hypertension patients, and improvement in the baroreflex function and cardiac autonomic regulation are proposed as the main possible mechanisms (Chaddha et al., 2019). Therefore, the loaded SDB technique, associated with larger blood pressure variation, and therefore, stronger baroreceptors stimulation and cardiac vagal modulation, is a good candidate to be investigated in hypertension management. In our study, BRS and BEI were similar between the SDB techniques. However, with the baroreflex operating within a larger range of blood pressure fluctuations, loaded SDB may improve baroreflex function more than other techniques when practiced over a longer period. Indeed, recent clinical trials in patients with hypertension have shown more reduction in blood pressure when using loaded SDB compared to SDB without load (Jones et al., 2010; Ublosakka-Jones et al., 2018; Ubolsakka-Jones et al., 2017). Whether such an effect is via improvement in baroreflex function remains to be investigated.

Reduced parasympathetic activity and BRS also have been reported in pain patients (Adlan et al., 2017; Bruehl et al., 2018). Considering the evidence on pain modulation by baroreceptors (Reyes Del Paso et al., 2014) and vagal nerve stimulation (Randich et al., 1990), it has been proposed that SDB may influence pain through these mechanisms, among others (Jafari et al., 2017). In this regard, loaded SDB may have more hypoalgesic effect than other SDB techniques, and this possibility warrants to be investigated.

The emotional response to different SDB techniques should not be overlooked (for review see Noble \& Hochman, 2019). The effect of SDB on hypertension may be due to its effect in reducing psychological (di)stress (Brown et al., 2013) which plays an important role in the etiology of hypertension (Johnson \& Xue, 2018). Also, one study showed that an SDB technique with more emphasis on relaxation is more effective in reducing pain than a technique requiring constant attention (Busch et al., 2012). The effect of emotion on pain has been shown by several studies (Bushnell et al., 2013). Loaded SDB is associated with higher arousal, less sense of control, and less pleasantness which may counteract its effect on pain or hypertension. It has been shown that baroreceptors stimulation does not modulate nociception under heightened arousal state 
(McIntyre et al., 2006). The emotional response to loaded SDB may be altered by more practice and motivation as patients with hypertension have shown good compliance even with higher inspiratory loads (e.g., $18 \mathrm{cmH}_{2} \mathrm{O}$ ) (Jones et al., 2010; Ublosakka-Jones et al., 2018). It remains to be investigated whether and through what psychophysiological mechanisms different SDB techniques have different effectiveness in reducing pain.

\section{6 | Study limitations}

Several study limitations should be noted. (1) We did not measure end-tidal carbon dioxide $\left(\mathrm{ETCO}_{2}\right)$ since an optimal measurement of $\mathrm{ETCO}_{2}$ would require using a breathing circuit, while we wanted to keep the SDB exercise similar to a real-world experience. Although a nasal or nasal/oral cannula could be used, we were concerned about the validity of such method as sampling locations would have been different between different breathing conditions (nose in UNB, mouth in PLB, and ITL in loaded SDB). Measuring $\mathrm{ETCO}_{2}$ would provide better information regarding putative differences in ventilation characteristics between different SDB techniques. (2) We used one respiratory belt and using a second belt, or other techniques such as respiratory inductance plethysmography, could provide more precise calibration of the respiratory signal by capturing movements at both thoracic and abdominal levels. (3) The duration of each breathing condition was limited to 3 min considering the feasibility of loaded SDB. Cardiovascular and emotional responses to longer duration of PLB and UNB warrants to be investigated. (4) We included participants with low levels of psychological symptoms. Including participants with higher levels of anxiety and/or including threat anticipation in the study would help to better investigate the ability of different SDB techniques to regulate the emotional responses. Finally, although the correct performance of all breathing techniques was monitored by the instructor observing the participant during training as well as during the main test, there was no "objective" measure for evaluating performance.

\section{7 | Conclusions}

Applying an inspiratory threshold load during SDB increases blood pressure variation, enhances the stimulation of the arterial baroreceptors, and leads to increased cardiac vagal modulation. However, this technique also increases arousal and reduces pleasantness and the sense of control during SDB, in short-term. In contrast, the PLB technique is associated with a low arousal state, more pleasantness, and more sense of control during SDB, while also increasing baroreceptors stimulation and cardiac vagal modulation (albeit less strongly than loaded SDB). Left and right UNB are associated with lower minute ventilation which can be beneficial for reducing the risk of hyperventilation during SDB. Whether these SDB techniques are equally effective in reducing pain and hypertension and through what mechanisms warrants further investigation.

\section{ACKNOWLEDGMENTS}

Authors would like to thank Mathijs Franssen and Jeroen Clarysse for providing technical support and Tom Duarte Silva Bans (Health Psychology, KU Leuven) for helping in data gathering during this study.

\section{CONFLICT OF INTEREST}

None.

\section{AUTHOR CONTRIBUTION}

Ali Gholamrezaei: Conceptualization; Data curation; Formal analysis; Investigation; Methodology; Project administration; Writing-original draft; Writing-review \& editing. Ilse Van Diest: Conceptualization; Funding acquisition; Investigation; Methodology; Supervision; Writing-review \& editing. Qasim Aziz: Conceptualization; Investigation; Methodology; Supervision; Writing-review \& editing. Johan WS Vlaeyen: Conceptualization; Funding acquisition; Investigation; Methodology; Supervision; Writing-review \& editing. Lukas Van Oudenhove: Conceptualization; Formal analysis; Funding acquisition; Investigation; Methodology; Supervision; Writing-review \& editing.

\section{ORCID}

Ali Gholamrezaei (iD https://orcid. org/0000-0001-8674-450X

Ilse Van Diest iD https://orcid.org/0000-0002-0048-774X

Qasim Aziz iD https://orcid.org/0000-0002-2718-2065

Johan W. S. Vlaeyen iD https://orcid.

org/0000-0003-0437-6665

Lukas Van Oudenhove iD https://orcid.

org/0000-0002-6540-3113

\section{REFERENCES}

Adlan, A. M., Paton, J. F. R., Lip, G. Y. H., Kitas, G. D., \& Fisher, J. P. (2017). Increased sympathetic nerve activity and reduced cardiac baroreflex sensitivity in rheumatoid arthritis. The Journal of Physiology, 595(3), 967-981. https://doi.org/10.1113/JP272944

Allen, B., \& Friedman, B. H. (2012). Positive emotion reduces dyspnea during slow paced breathing. Psychophysiology, 49(5), 690-696. https://doi.org/10.1111/j.1469-8986.2011.01344.x

Bernardi, L., Porta, C., Spicuzza, L., Bellwon, J., Spadacini, G., Frey, A. W., \& Tramarin, R. (2002). Slow breathing increases arterial baroreflex sensitivity in patients with chronic heart failure. Circulation, 105(2), 143-145. https://doi.org/10.1161/hc0202.103311 
Bernardi, L., Sleight, P., Bandinelli, G., Cencetti, S., Fattorini, L., Wdowczyc-Szulc, J., \& Lagi, A. (2001). Effect of rosary prayer and yoga mantras on autonomic cardiovascular rhythms: Comparative study. BMJ: British Medical Journal, 323(7327), 1446-1449. https://doi.org/10.1136/bmj.323.7327.1446

Bjelland, I., Dahl, A. A., Haug, T. T., \& Neckelmann, D. (2002). The validity of the Hospital Anxiety and Depression Scale. Journal of Psychosomatic Research, 52(2), 69-77. https://doi.org/10.1016/ S0022-3999(01)00296-3

Borg, G. A. (1982). Psychophysical bases of perceived exertion. Medicine and Science in Sports and Exercise, 14(5), 377-381. https://doi.org/10.1249/00005768-198205000-00012

Botha, C., Farmer, A. D., Nilsson, M., Brock, C., Gavrila, A. D., Drewes, A. M., \& Aziz, Q. (2015). Preliminary report: Modulation of parasympathetic nervous system tone influences oesophageal pain hypersensitivity. Gut, 64(4), 611-617. https://doi.org/10.1136/ gutjnl-2013-306698

Bradley, M. M., \& Lang, P. J. (1994). Measuring emotion: The self-assessment manikin and the semantic differential. Journal of Behavior Therapy and Experimental Psychiatry, 25(1), 49-59. https://doi. org/10.1016/0005-7916(94)90063-9

Brandani, J. Z., Mizuno, J., Ciolac, E. G., \& Monteiro, H. L. (2017). The hypotensive effect of Yoga's breathing exercises: A systematic review. Complementary Therapies in Clinical Practice, 28, 38-46. https://doi.org/10.1016/j.ctcp.2017.05.002

Brook, R. D., Appel, L. J., Rubenfire, M., Ogedegbe, G., Bisognano, J. D., Elliott, W. J., \& Rajagopalan, S. (2013). Beyond medications and diet: Alternative approaches to lowering blood pressure: A scientific statement from the American heart association. Hypertension, 61(6), 1360-1383. https://doi.org/10.1161/HYP.0b013e318293645f

Brown, R. P., \& Gerbarg, P. L. (2009). Yoga breathing, meditation, and longevity. Annals of the New York Academy of Sciences, 1172, 54 62. https://doi.org/10.1111/j.1749-6632.2009.04394.x

Brown, R. P., Gerbarg, P. L., \& Muench, F. (2013). Breathing practices for treatment of psychiatric and stress-related medical conditions. Psychiatric Clinics of North America, 36(1), 121-140. https://doi. org/10.1016/j.psc.2013.01.001

Bruehl, S., \& Chung, O. Y. (2004). Interactions between the cardiovascular and pain regulatory systems: An updated review of mechanisms and possible alterations in chronic pain. Neuroscience and Biobehavioral Reviews, 28(4), 395-414. https://doi.org/10.1016/j. neubiorev.2004.06.004

Bruehl, S., Olsen, R. B., Tronstad, C., Sevre, K., Burns, J. W., Schirmer, H., \& Rosseland, L. A. (2018). Chronic pain-related changes in cardiovascular regulation and impact on comorbid hypertension in a general population: The Tromso study. Pain, 159(1), 119-127. https://doi.org/10.1097/j.pain.0000000000001070

Busch, V., Magerl, W., Kern, U., Haas, J., Hajak, G., \& Eichhammer, P. (2012). The effect of deep and slow breathing on pain perception, autonomic activity, and mood processing-An experimental study. Pain Medicine, 13(2), 215-228. https://doi. org/10.1111/j.1526-4637.2011.01243.x

Bushnell, M. C., Ceko, M., \& Low, L. A. (2013). Cognitive and emotional control of pain and its disruption in chronic pain. Nature Reviews Neuroscience, 14(7), 502-511. https://doi.org/10.1038/ nrn3516

Bystritsky, A., Hovav, S., Sherbourne, C., Stein, M. B., Rose, R. D., Campbell-Sills, L., Golinelli, D., Sullivan, G., Craske, M. G., \& Roy-Byrne, P. P. (2012). Use of complementary and alternative medicine in a large sample of anxiety patients. Psychosomatics, 53(3), 266-272. https://doi.org/10.1016/j.psym.2011.11.009

Cappo, B. M., \& Holmes, D. S. (1984). The utility of prolonged respiratory exhalation for reducing physiological and psychological arousal in non-threatening and threatening situations. Journal of Psychosomatic Research, 28(4), 265-273. https://doi. org/10.1016/0022-3999(84)90048-5

Chaddha, A., Modaff, D., Hooper-Lane, C., \& Feldstein, D. A. (2019). Device and non-device-guided slow breathing to reduce blood pressure: A systematic review and meta-analysis. Complementary Therapies in Medicine, 45, 179-184. https://doi.org/10.1016/j. ctim.2019.03.005

Chalaye, P., Goffaux, P., Lafrenaye, S., \& Marchand, S. (2009). Respiratory effects on experimental heat pain and cardiac activity. Pain Medicine, 10(8), 1334-1340. https://doi. org/10.1111/j.1526-4637.2009.00681.x

Clarke, T. C., Nahin, R. L., Barnes, P. M., \& Stussman, B. J. (2016). Use of complementary health approaches for musculoskeletal pain disorders among adults: United States, 2012. National Health Statistics Reports, 98, 1-12. http://www.ncbi.nlm.nih.gov/ pubmed/27736632

Courtois, I., Gholamrezaei, A., Jafari, H., Lautenbacher, S., Van Diest, I., Van Oudenhove, L., \& Vlaeyen, J. W. (2020). Respiratory hypoalgesia? The effect of slow deep breathing on electrocutaneous, thermal, and mechanical pain. Journal of Pain, 21(5-6), 616-632.

Decramer, M. (2009). Response of the respiratory muscles to rehabilitation in COPD. Journal of Applied Physiology, 107(3), 971-976. https://doi.org/10.1152/japplphysiol.91459.2008

del Paso, G. A. R., Montoro, C., de Guevara, C. M. L., Duschek, S., \& Jennings, J. R. (2014). The effect of baroreceptor stimulation on pain perception depends on the elicitation of the reflex cardiovascular response: Evidence of the interplay between the two branches of the baroreceptor system. Biological Psychology, 101(1), 82-90. https://doi.org/10.1016/j.biopsycho.2014.07.004

Druss, B. G., \& Rosenheck, R. A. (2000). Use of practitioner-based complementary therapies by persons reporting mental conditions in the United States. Archives of General Psychiatry, 57(7), 708-714. https://doi.org/10.1001/archpsyc.57.7.708

Elstad, M., O’Callaghan, E. L., Smith, A. J., Ben-Tal, A., \& Ramchandra, R. (2018). Cardiorespiratory interactions in humans and animals: Rhythms for life. American Journal of Physiology-Heart and Circulatory Physiology, 315(1), H6-H17. https://doi.org/10.1152/ ajpheart.00701.2017

Farmer, D. G. S., Dutschmann, M., Paton, J. F. R., Pickering, A. E., \& McAllen, R. M. (2016). Brainstem sources of cardiac vagal tone and respiratory sinus arrhythmia. The Journal of Physiology, 594(24), 7249-7265. https://doi.org/10.1113/JP273164

Faul, F., Erdfelder, E., Lang, A.-G., \& Buchner, A. (2007). G*Power 3: A flexible statistical power analysis program for the social, behavioral, and biomedical sciences. Behavior Research Methods, 39(2), 175-191. https://doi.org/10.3758/BF03193146

Fessler, H. E., Brower, R. G., Wise, R. A., \& Permutt, S. (1992). Effects of positive end-expiratory pressure on the canine venous return curve. The American Review of Respiratory Disease, 146(1), 4-10. https://doi.org/10.1164/ajrccm/146.1.4

Fonkoue, I., Marvar, P. J., Norrholm, S. D., Kankam, M. L., Li, Y., DaCosta, D., \& Park, J. (2018). Acute effects of device-guided slow breathing on sympathetic nerve activity and baroreflex sensitivity in posttraumatic stress disorder. American Journal of Physiology. 
Heart and Circulatory Physiology, 29(6), 386-391. https://doi. org/10.1152/ajpheart.00098.2018

Gholamrezaei, A., Van Diest, I., Aziz, Q., Vlaeyen, J. W. S., \& Van Oudenhove, L. (2019). Influence of inspiratory threshold load on cardiovascular responses to controlled breathing at $0.1 \mathrm{~Hz}$. Psychophysiology, 56(11), e13447. https://doi.org/10.1111/ psyp. 13447

Gilbert, C. (2014). Interaction of psychological and emotional variables with breathing dysfunction. In L. Chaitow, D. Bradley, \& C. Gilbert (Eds.), Recognizing and treating breathing disorders: A multidisciplinary approach (2nd ed., pp. 79-91). Churchill Livingstone.

Harada, D., Asanoi, H., Takagawa, J., Ishise, H., Ueno, H., Oda, Y., \& Inoue, H. (2014). Slow and deep respiration suppresses steady-state sympathetic nerve activity in patients with chronic heart failure: From modeling to clinical application. AJP: Heart and Circulatory Physiology, 307(8), H1159-H1168. https://doi.org/10.1152/ajphe art.00109.2014

Holland, A. E., Hill, C. J., Jones, A. Y., \& McDonald, C. F. (2012). Breathing exercises for chronic obstructive pulmonary disease. The Cochrane Database of Systematic Reviews, 10, CD008250. https:// doi.org/10.1002/14651858.CD008250.pub2

Holm, S. (1979). A simple sequentially rejective multiple test procedure. Source: Scandinavian Journal of Statistics, 6(2), 65-70. https://doi. org/10.2307/4615733

Jackson, C. (2015). Trends in the use of complementary health approaches among adults in the United States: New Data. Holistic Nursing Practice, 29(3), 178-179. https://doi.org/10.1097/ HNP.0000000000000088

Jafari, H., Courtois, I., Van den Bergh, O., Vlaeyen, J. W. S., \& Van Diest, I. (2017). Pain and respiration: A systematic review. Pain, 158(6), 995-1006. https://doi.org/10.1097/j.pain.0000000000 000865

Jafari, H., Gholamrezaei, A., Franssen, M., Van Oudenhove, L., Aziz, Q., Van den Bergh, O., \& Van Diest, I. (2020). Can slow deep breathing reduce pain? An experimental study exploring mechanisms. The Journal of Pain: Official Journal of the American Pain Society. https://doi.org/10.1016/j.jpain.2019.12.010

Jella, S. A., \& Shannahoff-Khalsa, D. S. (1993). The effects of unilateral forced nostril breathing on cognitive performance. The International Journal of Neuroscience, 73, 61-68. https://doi.org/10.3109/00207 459308987211

Johnson, A. K., \& Xue, B. (2018). Central nervous system neuroplasticity and the sensitization of hypertension. Nature Reviews Nephrology, 14(12), 750-766. https://doi.org/10.1038/s41581-018-0068-5

Jones, C. U., Sangthong, B., \& Pachirat, O. (2010). An inspiratory load enhances the antihypertensive effects of home-based training with slow deep breathing: A randomised trial. Journal of Physiotherapy, 56(3), 179-186. https://doi.org/10.1016/S1836-9553(10)70023-0

Joseph, C. N., Porta, C., Casucci, G., Casiraghi, N., Maffeis, M., Rossi, M., \& Bernardi, L. (2005). Slow breathing improves arterial baroreflex sensitivity and decreases blood pressure in essential hypertension. Hypertension, 46(4), 714-718. https://doi.org/10.1161/01. HYP.0000179581.68566.7d

Karemaker, J. M. (2009). Counterpoint: Respiratory sinus arrhythmia is due to the baroreflex mechanism. Journal of Applied Physiology, 106(5), 1742-1743; discussion 1744. https://doi.org/10.1152/jappl physiol.91107.2008a

Kessler, R. C., Soukup, J., Davis, R. B., Foster, D. F., Wilkey, S. A., Van Rompay, M. I., \& Eisenberg, D. M. (2001). The use of complementary and alternative therapies to treat anxiety and depression in the United States. The American Journal of Psychiatry, 158(2), 289-294. https://doi.org/10.1176/appi.ajp.158.2.289

Killian, K. J., Bucens, D. D., \& Campbell, E. J. (1982). Effect of breathing patterns on the perceived magnitude of added loads to breathing. Journal of Applied Physiology: Respiratory, Environmental and Exercise Physiology, 52(3), 578-584. https://doi.org/10.1152/ jappl.1982.52.3.578

Kromenacker, B. W., Sanova, A. A., Marcus, F. I., Allen, J. J. B., \& Lane, R. D. (2018). Vagal mediation of low-frequency heart rate variability during slow yogic breathing. Psychosomatic Medicine, 80(6), 581-587. https://doi.org/10.1097/PSY.0000000000000603

Lalande, S., Luoma, C. E., Miller, A. D., \& Johnson, B. D. (2012). Effect of changes in intrathoracic pressure on cardiac function at rest and during moderate exercise in health and heart failure. Experimental Physiology, 97(2), 248-256. https://doi.org/10.1113/ expphysiol.2011.061945

Lehrer, P. M., Vaschillo, E., Vaschillo, B., Lu, S.-E., Eckberg, D. L., Edelberg, R., \& Hamer, R. M. (2003). Heart rate variability biofeedback increases baroreflex gain and peak expiratory flow. Psychosomatic Medicine, 65(5), 796-805. https://doi. org/10.1097/01.psy.0000089200.81962.19

Macefield, V. G., \& Henderson, L. A. (2019). Identification of the human sympathetic connectome involved in blood pressure regulation. NeuroImage, 202, 116119. https://doi.org/10.1016/j.neuro image.2019.116119

Mancia, G., \& Grassi, G. (2014). The autonomic nervous system and hypertension. Circulation Research, 114(11), 1804-1814. https:// doi.org/10.1161/CIRCRESAHA.114.302524

Martin, S. L., Kerr, K. L., Bartley, E. J., Kuhn, B. L., Palit, S., Terry, E. L., \& Rhudy, J. L. (2012). Respiration-induced hypoalgesia: Exploration of potential mechanisms. Journal of Pain, 13(8), 755763. https://doi.org/10.1016/j.jpain.2012.05.001

McCaul, K. D., Solomon, S., \& Holmes, D. S. (1979). Effects of paced respiration and expectations on physiological and psychological responses to threat. Journal of Personality and Social Psychology, 37(4), 564-571. https://doi.org/10.1037//0022-3514.37.4.564

McGinley, J. J., \& Friedman, B. H. (2015). Autonomic responses to lateralized cold pressor and facial cooling tasks. Psychophysiology, 52(3), 416-424. https://doi.org/10.1111/psyp.12332

McIntyre, D., Edwards, L., Ring, C., Parvin, B., \& Carroll, D. (2006). Systolic inhibition of nociceptive responding is moderated by arousal. Psychophysiology, 43(3), 314-319. https://doi. org/10.1111/j.1469-8986.2006.00407.x

Melo, H. M., Martins, T. C., Nascimento, L. M., Hoeller, A. A., Walz, R., \& Takase, E. (2018). Ultra-short heart rate variability recording reliability: The effect of controlled paced breathing. Annals of Noninvasive Electrocardiology: the Official Journal of the International Society for Holter and Noninvasive Electrocardiology Inc, 23(5), e12565. https://doi.org/10.1111/ anec. 12565

Modesti, P. A., Ferrari, A., Bazzini, C., \& Boddi, M. (2015). Time sequence of autonomic changes induced by daily slow-breathing sessions. Clinical Autonomic Research: Official Journal of the Clinical Autonomic Research Society, 25(2), 95-104. https://doi. org/10.1007/s10286-014-0255-9

Mohrman, D. E., \& Lois, J. H. (2018). Cardiovascular physiology (9th ed). : McGraw-Hill Education LLC.

Nahin, R. L., Stussman, B. J., \& Herman, P. M. (2015). Out-of-pocket expenditures on complementary health approaches associated with painful health conditions in a nationally representative adult 
sample. The Journal of Pain: Official Journal of the American Pain Society, 16(11), 1147-1162. https://doi.org/10.1016/j. jpain.2015.07.013

Noble, D. J., \& Hochman, S. (2019). Hypothesis: Pulmonary afferent activity patterns during slow, deep breathing contribute to the neural induction of physiological relaxation. Frontiers in Physiology, 10, 1176. https://doi.org/10.3389/fphys.2019.01176

Pal, G. K., Agarwal, A., Karthik, S., Pal, P., \& Nanda, N. (2014). Slow yogic breathing through right and left nostril influences sympathovagal balance, heart rate variability, and cardiovascular risks in young adults. North American Journal of Medical Sciences, 6(3), 145-151. https://doi.org/10.4103/1947-2714.128477

Pallanch, J. F., McCaffrey, T. V., \& Kern, E. B. (1985). Normal nasal resistance. Otolaryngology-Head and Neck Surgery: Official Journal of American Academy of Otolaryngology-Head and Neck Surgery, 93(6), 778-785. https://doi.org/10.1177/019459988509300616

Parati, G., Di Rienzo, M., Bertinieri, G., Pomidossi, G., Casadei, R., Groppelli, A., \& Mancia, G. (1988). Evaluation of the baroreceptor-heart rate reflex by 24-hour intra-arterial blood pressure monitoring in humans. Hypertension, 12(2), 214-222. https://doi. org/10.1161/01.hyp.12.2.214

Prasad, K., Sharma, V., Lackore, K., Jenkins, S. M., Prasad, A., \& Sood, A. (2013). Use of complementary therapies in cardiovascular disease. The American Journal of Cardiology, 111(3), 339-345. https://doi.org/10.1016/j.amjcard.2012.10.010

Price, A., \& Eccles, R. (2016). Nasal airflow and brain activity: Is there a link? The Journal of Laryngology and Otology, 130(9), 794-799. https://doi.org/10.1017/S0022215116008537

Raghuraj, P., \& Telles, S. (2008). Immediate effect of specific nostril manipulating yoga breathing practices on autonomic and respiratory variables. Applied Psychophysiology and Biofeedback, 33(2), 65-75. https://doi.org/10.1007/s10484-008-9055-0

Randich, A., Ren, K., \& Gebhart, G. F. (1990). Electrical stimulation of cervical vagal afferents. II. Central relays for behavioral antinociception and arterial blood pressure decreases. Journal of Neurophysiology, 64(4), 1115-1124. https://doi.org/10.1152/ jn.1990.64.4.1115

Rincon Soler, A. I., Silva, L. E. V., Fazan, R., \& Murta Junior, L. O. (2017). The impact of artifact correction methods of RR series on heart rate variability parameters. Journal of Applied Physiology, 124(3), 646-652. https://doi.org/10.1152/japplphysiol.00927.2016

Russo, M. A., Santarelli, D. M., \& O'Rourke, D. (2017). The physiological effects of slow breathing in the healthy human. Breathe (Sheffield, England), 13(4), 298-309. https://doi.org/10.1183/20734 735.009817

Sakakibara, M., \& Hayano, J. (1996). Effect of slowed respiration on cardiac parasympathetic response to threat. Psychosomatic Medicine, 58(1), 32-37. https://doi.org/10.1097/00006842-199601000-00006

Schulz, S., Adochiei, F.-C., Edu, I.-R., Schroeder, R., Costin, H., Bär, K.-J., \& Voss, A. (2013). Cardiovascular and cardiorespiratory coupling analyses: A review. Philosophical Transactions. Series A, Mathematical, Physical, and Engineering Sciences, 371, 20120191. https://doi.org/10.1098/rsta.2012.0191

Shannahoff-Khalsa, D. S. (1991). Lateralized rhythms of the central and autonomic nervous systems. International Journal of Psychophysiology: Official Journal of the International Organization of Psychophysiology, 11(3), 225-251. https://doi. org/10.1016/0167-8760(91)90317-Q

Shannahoff-Khalsa, D. S., \& Kennedy, B. (1993). The effects of unilateral forced nostril breathing on the heart. The International Journal of Neuroscience, 73(1-2), 47-60. https://doi.org/10.3109/00207 459308987210

Sin, P. Y. W., Galletly, D. C., \& Tzeng, Y. C. (2010). Influence of breathing frequency on the pattern of respiratory sinus arrhythmia and blood pressure: Old questions revisited. American Journal of Physiology. Heart and Circulatory Physiology, 298(5), H1588-H1599. https://doi.org/10.1152/ajpheart.00036.2010

Spahija, J. A., \& Grassino, A. (1996). Effects of pursed-lips breathing and expiratory resistive loading in healthy subjects. Journal of Applied Physiology, 80(5), 1772-1784. https://doi.org/10.1152/ jappl.1996.80.5.1772

Spinhoven, P., Ormel, J., Sloekers, P. P., Kempen, G. I., Speckens, A. E., \& Van Hemert, A. M. (1997). A validation study of the Hospital Anxiety and Depression Scale (HADS) in different groups of Dutch subjects. Psychological Medicine, 27(2), 363-370. https://doi. org/10.1017/s0033291796004382

Spruyt, A., Clarysse, J., Vansteenwegen, D., Baeyens, F., \& Hermans, D. (2010). Affect 4.0: A free software package for implementing psychological and psychophysiological experiments. Experimental Psychology, 57(1), 36-45. https://doi.org/10.1027/1618-3169/ a000005

Stewart, M. G., Witsell, D. L., Smith, T. L., Weaver, E. M., Yueh, B., \& Hannley, M. T. (2004). Development and validation of the Nasal Obstruction Symptom Evaluation (NOSE) Scale. Otolaryngologyhead and Neck Surgery, 130(2), 157-163. https://doi.org/10.1016/j. otohns.2003.09.016

Szulczewski, M. T. (2019). An anti-hyperventilation instruction decreases the drop in end-tidal $\mathrm{CO}_{2}$ and symptoms of hyperventilation during breathing at $0.1 \mathrm{~Hz}$. Applied Psychophysiology and Biofeedback, 44(3), 247-256. https://doi.org/10.1007/s10484-019-09438-y

Taha, B. H., Simon, P. M., Dempsey, J. A., Skatrud, J. B., \& Iber, C. (1995). Respiratory sinus arrhythmia in humans: An obligatory role for vagal feedback from the lungs. Journal of Applied Physiology, 78(2), 638-645. https://doi.org/10.1152/jappl.1995.78.2.638

Task Force of the European Society of Cardiology and the North American Society of Pacing and Electrophysiology. (1996). Heart rate variability: Standards of measurement, physiological interpretation and clinical use. Circulation, 93(5), 1043-1065. https://doi. org/10.1161/01.CIR.93.5.1043

Taylor, J. A., Myers, C. W., Halliwill, J. R., Seidel, H., \& Eckberg, D. L. (2001). Sympathetic restraint of respiratory sinus arrhythmia: Implications for vagal-cardiac tone assessment in humans. American Journal of Physiology. Heart and Circulatory Physiology, 280(6), H2804-H2814. https://doi.org/10.1152/ajpheart.2001.280.6.H2804

Tzeng, Y. C., Sin, P. Y. W., Lucas, S. J. E., \& Ainslie, P. N. (2009). Respiratory modulation of cardiovagal baroreflex sensitivity. Journal of Applied Physiology, 107(3), 718-724. https://doi. org/10.1152/japplphysiol.00548.2009

Ublosakka-Jones, C., Tongdee, P., Pachirat, O., \& Jones, D. A. (2018). Slow loaded breathing training improves blood pressure, lung capacity and arm exercise endurance for older people with treated and stable isolated systolic hypertension. Experimental Gerontology, 108, 48-53. https://doi.org/10.1016/j.exger.2018.03.023

Ubolsakka-Jones, C., Sangthong, B., Khrisanapant, W., \& Jones, D. A. (2017). The effect of slow-loaded breathing training on the blood pressure response to handgrip exercise in patients with isolated systolic hypertension. Hypertension Research: Official Journal of the Japanese Society of Hypertension, 40, 1-7. https://doi.org/10.1038/hr.2017.54

Van Diest, I., Verstappen, K., Aubert, A. E., Widjaja, D., Vansteenwegen, D., \& Vlemincx, E. (2014). Inhalation/Exhalation ratio modulates 
the effect of slow breathing on heart rate variability and relaxation. Applied Psychophysiology and Biofeedback, 39(3-4), 171-180. https://doi.org/10.1007/s10484-014-9253-x

van Zijl, F. V. W. J., Timman, R., \& Datema, F. R. (2017). Adaptation and validation of the Dutch version of the nasal obstruction symptom evaluation (NOSE) scale. European Archives of Oto-RhinoLaryngology: Official Journal of the European Federation of Oto-Rhino-Laryngological Societies (EUFOS): Affiliated with

the German Society for Oto-Rhino-Laryngology_Head and Neck Surgery, 274(6), 2469-2476. https://doi.org/10.1007/s0040 5-017-4486-y

Wang, Y.-P., Kuo, T. B. J., Lai, C.-T., Chu, J.-W., \& Yang, C. C. H. (2013). Effects of respiratory time ratio on heart rate variability and spontaneous baroreflex sensitivity. Journal of Applied Physiology, 115, 1648-1655. https://doi.org/10.1152/japplphysi ol.00163.2013

Zautra, A. J., Fasman, R., Davis, M. C., \& Craig, A. D. (2010). The effects of slow breathing on affective responses to pain stimuli: An experimental study. Pain, 149(1), 12-18. https://doi.org/10.1016/j. pain.2009.10.001

Zelano, C., Jiang, H., Zhou, G., Arora, N., Schuele, S., Rosenow, J., \& Gottfried, J. A. (2016). Nasal respiration entrains human limbic oscillations and modulates cognitive function. The Journal of Neuroscience: The Official Journal of the Society for Neuroscience, 36(49), 12448-12467. https://doi.org/10.1523/JNEUR OSCI.2586-16.2016

\section{SUPPORTING INFORMATION}

Additional supporting information may be found online in the Supporting Information section.

TABLE S1 Results of pairwise contrasts of estimated tidal volume $(\mathrm{mL})$ between the breathing conditions

TABLE S2 Results of pairwise contrasts of estimated minute ventilation (L) between the breathing conditions

TABLE S3 Results of pairwise contrasts of average systolic blood pressure between the breathing conditions

TABLE S4 Results of pairwise contrasts of average diastolic blood pressure between the breathing conditions
TABLE S5 Results of pairwise contrasts of the amplitude of blood pressure variability between the breathing conditions

TABLE S6 Results of pairwise contrasts of RMSSD between the breathing conditions

TABLE S7 Results of pairwise contrasts of respiratory sinus arrythmia between the breathing conditions

TABLE S8 Dyspnea, arousal, valence, and dominance scores between the breathing conditions

TABLE S9 Results of pairwise contrasts of dyspnea between the breathing conditions

TABLE S10 Result of pairwise contrasts of emotional response, arousal between the breathing conditions

TABLE S11 Results of pairwise contrasts of emotional response, valence between the breathing conditions

TABLE S12 Results of pairwise contrasts of emotional response, dominance between the breathing conditions

Table S13 Comparison of respiratory and cardiovascular variables between breathing conditions and the resting baselinea

FIGURE S1 Power spectrum density (PSD) of the respiratory belt signal (A), RR-interval (B), and systolic blood pressure $(C)$ in the breathing conditions: LUNB left unilateral nostril breathing; PLB pursed-lips breathing; RUNB right unilateral nostril breathing; SDB slow deep breathing FIGURE S2 Mediation analysis examining the effect of breathing conditions (block) on the amplitude of systolic blood pressure variation (BPV) (model A), having respiratory sinus arrhythmia (RSA) as the mediator (model B)

How to cite this article: Gholamrezaei A, Van Diest I, Aziz Q, Vlaeyen JWS, Van Oudenhove L.

Psychophysiological responses to various slow, deep breathing techniques. Psychophysiology.

2021;58:e13712. https://doi.org/10.1111/psyp.13712 